\title{
Impact of implementation of a breech clinic in a tertiary hospital
}

\author{
S. Derisbourg ${ }^{1 *}$ (D), E. Costa ${ }^{1}$, L. De Luca', S. Amirgholami ${ }^{1}$, V. Bogne Kamdem' , A. Vercoutere ${ }^{1}$, W. H. Zhang ${ }^{2}$, \\ S. Alexander ${ }^{3}$, P. M. Buekens ${ }^{4}$, Y. Englert ${ }^{1,2}$, A. Pintiaux $^{1}$ and C. Daelemans ${ }^{1}$
}

\begin{abstract}
Background: The incidence of breech presentation in single pregnancies at term is between three to $5 \%$. In order to support eligible women in their choice of mode of delivery, a dedicated breech clinic with a care pathway was developed in December 2015 in a tertiary referral centre in Brussels.

The primary objective of this study was to evaluate the vaginal birth rate before and after the introduction of a dedicated breech clinic. The secondary objective was to compare the early neonatal outcomes before and after the breech clinic was introduced.
\end{abstract}

Methods: This was a single centre retrospective and prospective study. The inclusion criteria were term (from 37 weeks), singleton fetus and breech presentation at delivery. The exclusion criteria were suspected intrauterine growth restriction, severe fetal malformations and intrauterine fetal demise. We used a composite outcome as an indicator of neonatal morbidity and mortality.

Results: After the introduction of the breech clinic, we observed a significant increase in planned vaginal delivery from 7.4\% (12/162) to 53.0\% (61/115) (OR: 13.5; 95\% Cl: 6.7-27.0). The effective vaginal breech delivery rate (planned and unexpected) significantly increased from 4.3\% (7/162) pre-implementation of breech clinic to 43.5\% (50/115) post-implementation (OR: 17.0; 95\% Cl: 7.3-39.6). Neonatal outcomes were not statistically different between the before and after periods.

Conclusion: The introduction of a dedicated breech clinic has led to an increase in vaginal deliveries for breech babies without adversely affecting neonatal outcomes.

Keywords: Breech delivery, Breech clinic, Care-pathway, Mode of delivery, Neonatal outcome

\section{Background}

Breech presentation occurs in three to $5 \%$ of singleton pregnancies after 37 weeks of gestational age (GA) [1]. The publication of the Term Breech Trial (TBT) in 2000 [2] had a significant impact on obstetric practice with many countries and international organisations recommending against vaginal birth. However, more recently, and mostly due to concerns surrounding the global rise

\footnotetext{
* Correspondence: sara.derisbourg@erasme.ulb.ac.be

'Department of Obstetrics and Gynecology, Cliniques Universitaires de Bruxelles, Hôpital Erasme, Université Libre de Bruxelles (ULB), 808 route de Lennik, B-1070 Bruxelles, Belgium

Full list of author information is available at the end of the article
}

in caesarean section rates and on-going criticisms about the methodology and the interpretation of the TBT, this option has been re-evaluated. The International Federation of Gynecology and Obstetrics (FIGO) [3], Le Collège National des Gynécologues et Obstétriciens Français (CNGOF) [4], the Royal College of Obstetricians and Gynaecologists (RCOG) [1] and the Society of Obstetricians and Gynaecologists of Canada (SOGC) [5] now support the option of vaginal breech birth $[4,6,7]$.

The Cochrane Review of 2015 revealed a lower neonatal morbidity and mortality in the planned C-section group compared with the vaginal delivery group with an

(c) The Author(s). 2020 Open Access This article is licensed under a Creative Commons Attribution 4.0 International License, which permits use, sharing, adaptation, distribution and reproduction in any medium or format, as long as you give appropriate credit to the original author(s) and the source, provide a link to the Creative Commons licence, and indicate if changes were made. The images or other third party material in this article are included in the article's Creative Commons licence, unless indicated otherwise in a credit line to the material. If material is not included in the article's Creative Commons licence and your intended use is not permitted by statutory regulation or exceeds the permitted use, you will need to obtain permission directly from the copyright holder. To view a copy of this licence, visit http://creativecommons.org/licenses/by/4.0/. The Creative Commons Public Domain Dedication waiver (http://creativecommons.org/publicdomain/zero/1.0/) applies to the data made available in this article, unless otherwise stated in a credit line to the data. 
Odds Ratio (OR) of 0.3 and a $95 \%$ confidence interval (95\% CI) of 0.2-0.6. However the TBT contributed to the majority of cases to the meta-analysis [2]. Multiple criticisms of this trial have already been published with many suggesting that selection was biased and expertise in breech delivery was suboptimal in some participating centres $[8,9]$. Perhaps of more significance, was the failure to demonstrate any statistically significant difference in childhood outcomes between the two modes of birth at 2 years of age [10].

The PREMODA [7] study conducted in Belgium and France used similar outcome criteria as the TBT [2] but the methodology was prospective observational rather than a randomised trial. There was no specific management protocol, but the items used as a basis for deciding the mode of birth were: ultrasound evaluation of fetal size and cephalic flexion, maternal pelvimetry, woman's desire to attempt a vaginal birth. The elements for managing and monitoring the labour were: the obstetrician's self-assessed expertise in vaginal breech and continuous electronic fetal monitoring. The outcomes of 2526 planned vaginal breeches were compared to the outcomes of 5579 planned C-sections in 174 units. Neonatal short-term morbidity (five-minute Apgar score under four, injuries and intubation) was more frequent in the planned vaginal group compared to the planned C-section group (OR 8.92 (95\% CI 1.0-79.8), 3.90 (2.4$6.34)$ and $1.82(1.08-3.06)$ respectively). No other difference was found [7]. However since the publication of the TBT, the $\mathrm{C}$-section rate for breech presentation has drastically increased in Europe [11-14] and expertise in vaginal breech birth has withered away.

Arguments against the conclusions of the TBT [2], the positive results of the PREMODA study [7], and globally rising $\mathrm{C}$-section rates, have led to a reconsideration of vaginal breech birth by various authorities $[1,4-6]$. A secondary analysis of the TBT highlighted the beneficial effect of the presence of an experienced clinician at breech births [15]. The recently published guideline by the RCOG [5] on the management of breech presentation suggests that 'clinicians should counsel women in an unbiased way that ensures a proper understanding of the absolute as well as the relative risks of their different options' and that 'the presence of a skilled birth attendant is essential for safe vaginal breech birth' [1]. In Belgium, the Frenchspeaking Belgian guidelines [16] never ceased to recommend "selected vaginal breech" approach. However, compared to other European countries with the same policy, the national rate of vaginal birth in 2015 according to Euro-peristat [17] was low: $10.3 \%$ in Belgium, compared to $25.2 \%$ in France, a country with very similar guidelines, or $34.5 \%$ in Norway [17].

A returned focus on vaginal breech deliveries needs to be well planned. In order to support eligible women in their choice of mode of delivery, and to standardise care and counselling [18], a 'breech clinic' with a dedicated care pathway and a vaginal breech protocol were developed in our unit starting from December 2015. In order, to effectively support women and clinicians, a 24-h oncall specialist team was also established as suggested by Walker et al. [18, 19].

The primary objective of this hybrid retrospective and prospective study was to compare the planned and observed vaginal delivery rates before and after the implementation of the breech clinic. The secondary objective was to compare the early neonatal outcomes.

\section{Breech clinic}

\section{Setting up the breech clinic}

The breech clinic was developed in Cliniques Universitaires de Bruxelles 'Hôpital Erasme' a tertiary referral centre and the academic hospital of the 'Université Libre de Bruxelles' (ULB) in Brussels, Belgium. The breech clinic was not developed following formal program theory techniques ante hoc. The model aimed to remediate poor adherence to Belgian breech guidelines and included: new skills development, a dedicated team and clinic, and a rota of on-call breech specialists. This type of intervention has already been reported for external cephalic version (ECV) in breech [20], but also for vaginal birth after C-section, including a trial [21], or management of early pregnancy bleeding [22] Belgian breech guidelines [16], as in some Nordic countries, consider the appropriate pathway includes timely recognition and routine consideration of ECV. And in case of unsuccessful ECV a discussion with the parents should lead to a partnership decision of the most appropriate mode of delivery. Our philosophy is to promote physiological labour and delivery with as few medical interventions as is safely possible. The maternity has around 2000 deliveries per year and since 2014 has also developed the first alongside midwifery unit in Belgium 'the Cocoon' [23].

Prior to the introduction of the breech clinic, no structured pathway of care for women with a breech presentation existed. In December 2015, such a care pathway was developed with dedicated appointments and an information leaflet for women (Supplementary material 1) explaining the ECV, the different modes of delivery and our antenatal education program. Since May 2016, each component of the service has been fully functional.

\section{Professionals}

Six obstetricians and two midwives are dedicated to the breech clinic. Four of the obstetricians are experienced but two of the younger obstetricians still need direct supervision [19]. Two of the six are responsible for in- 
depth counselling, perform the ECV and select eligible women. One is regularly involved in the teaching of midwives, obstetric trainees and other colleagues [19]. The two midwives are responsible for the more physical aspects of a planned vaginal birth: training in pushing, maternal positions and pain management. For the delivery, one or two of the six "breech" obstetricians are always present and all support each other [24]. All members must have a training update in breech delivery at least once every year (local or international training, simulation, local or international congress and local review of cases with birth videos and/or medical records).

\section{Care pathway}

If the fetus is in breech position at the routine ultrasound around 32 weeks of GA, the woman is referred to the breech clinic. An appointment is scheduled at around 35-36 weeks of GA to explain the ECV procedure, including the risks and benefits. If a woman opts for an ECV, this takes place at between 36 and 37 weeks of GA (Fig. 1). One to three ECV are scheduled per week. In order to concentrate practice two of the obstetricians of the breech clinic perform it [25]. If the ECV is unsuccessful, in order to comply with the French-speaking Belgian college guidelines, a pelvimetry by computerized

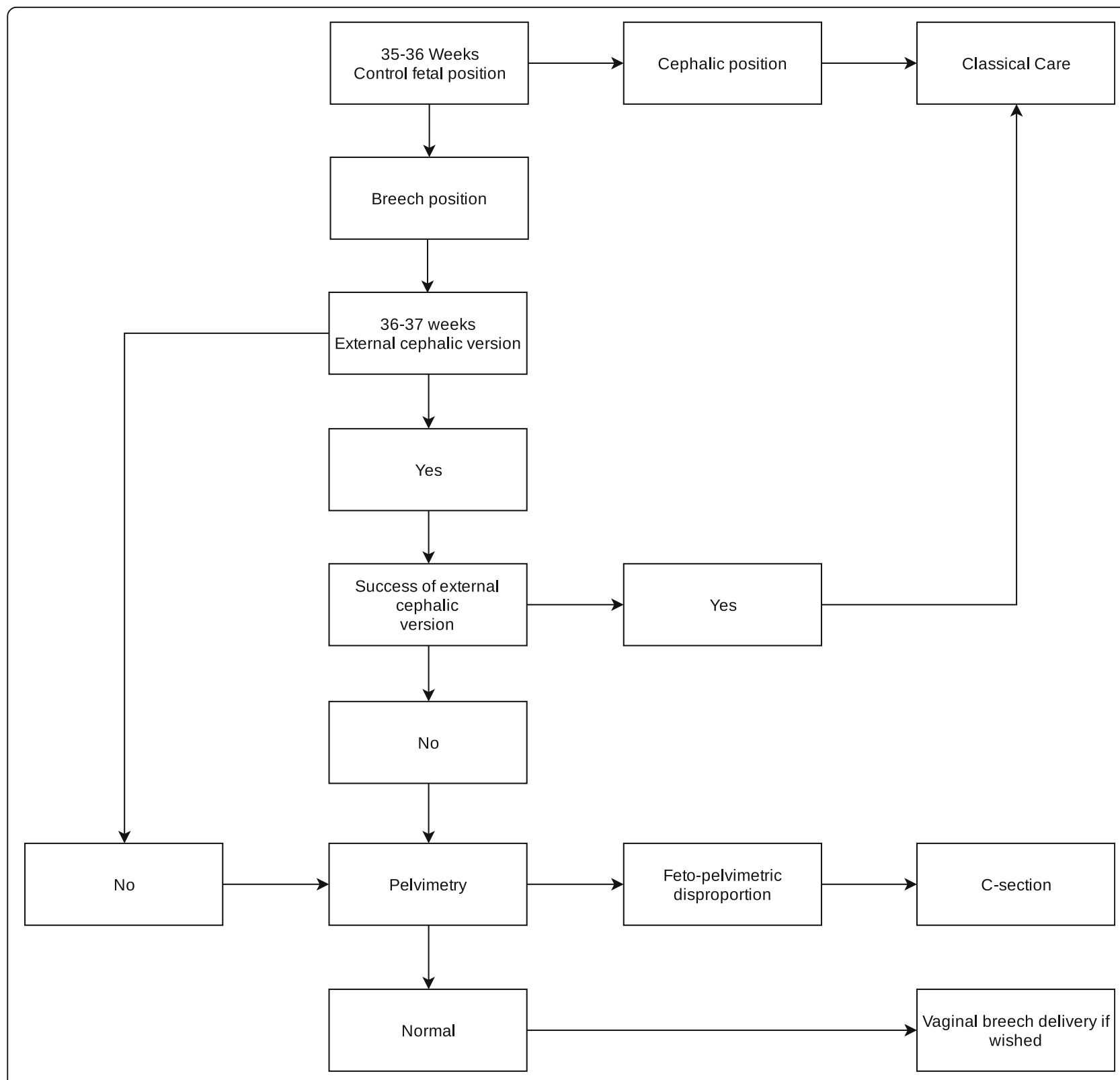

Fig. 1 Care pathway of the breech clinic 
tomography (CT) scan is performed for all women [16] even though there is minimal evidence to support its use. As MRI-pelvimetry is less accessible in our service, most pelvimetries were performed using a CT-scan. Following the pelvimetry, an appointment is scheduled with one of the obstetricians from the breech clinic team to discuss the options for delivery, their relative risks and benefits and the management of labour, in case of a vaginal delivery attempt. Finally, if the woman opts for a vaginal delivery, we organise several sessions with a midwife in order to adequately prepare the woman for the labour and the delivery. All the women are offered the Erasme breech clinic leaflet (Supplementary material 1) containing information about ECV and breech delivery (vaginal delivery and $\mathrm{C}$-section). The obstetricians work in accordance with the local guidelines and are comfortable and skilled at breech deliveries.

\section{Eligibility criteria for a breech delivery attempt}

- Motivated expectant woman

- Estimated fetal weight above $2500 \mathrm{~g}$

- GA more than 37 weeks

- CT-pelvimetry deemed adequate

- No cephalo-pelvimetric disproportion

- No other indication for C-section (two or more previous C-sections, placenta praevia, etc.)

- No hyperextension of the fetal head

\section{Management of labour and delivery}

An ultrasound is performed at the time of the admission to the delivery suite to confirm the presentation and to exclude hyperextension of the fetal head. If indicated, induction of labour is performed ideally with favourable cervix (Bishop score $>6-7$ ). Continuous electronic fetal monitoring is mandatory during the labour and if necessary, oxytocin and/or artificial rupture of membranes are/is used for augmentation. Epidural analgesia is available and used based on maternal request rather than systematically. During the birth, physiological techniques are preferred: no unnecessary manoeuvre is performed and the woman make their own decisions regarding birthing positions including, but not restricted to, upright or 'on all fours' positions [26]. Episiotomy is individualised and not performed systematically.

\section{Methods}

\section{Study design}

This was a single centre observational study, specifically designed to evaluate the impact of a dedicated breech clinic on vaginal breech births and on perinatal outcomes. Data were collected from the 1st of January 2013 to the 31st of November 2015 prior to the creation of the breech clinic and from the 1st of May 2016 to the 1st of October 2019 once the clinic was fully operational. From the 1st of March 2018, the patients were prospectively recruited and gave their informed consent to participate in the study. Prior to this date information was accessed using the medical records, without individual patient consent, with the approval of the local ethics research committee.

\section{Participants}

The inclusion criteria were as follows: live term, singleton fetus in breech presentation at the time of delivery. Women who delivered during the transition period (5 months from the 1st of December 2015 until the 30th of April 2016) were excluded. Other exclusion criteria were: severe fetal malformations, intrauterine growth restriction $(<10$ th centile) and intrauterine fetal demise or any obstetric contraindication to labour or vaginal delivery (e.g. placenta praevia or multiple previous $\mathrm{C}$-sections) (Fig. 2).

\section{Data collection}

The following variables were extracted from the hospital electronic database:

1. The baseline maternal characteristics: maternal age, body mass index (BMI), ethnicity (Europe for countries on the European continent, sub-saharan Africa for the African countries South of the Sahara, and Mediterranean Basin for the countries around the Mediterranean Sea except for France, Spain, Italy, and Greece, Other for the other countries or mixed race), assisted reproductive technology, smoking, parity, uterine scar, ECV attempts.

2. The mode of delivery: unexpected breech birth, planned and actual mode of delivery.

3. The neonatal outcomes: GA at birth, birth weight, 5-min Apgar score, arterial cord blood $\mathrm{pH}$, arterial cord blood base deficit, neonatal intensive care unit (NICU) admission, parenteral and tubal feeding and duration, birth trauma, invasive ventilation support (intubation) or non-invasive ventilation support (continuous positive airway pressure for example) and duration, seizures, intracerebral ventricular haemorrhage, neonatal death.

\section{Outcomes}

Our primary outcome was to compare the planned and actual mode of delivery before and after the introduction of the breech clinic. Our secondary outcome was to compare the short-term neonatal outcomes. A composite marker of perinatal outcome, which was similar to that proposed previously by the TBT [2] and the PREMODA study [7] was used (see Table 1 for the comparison of composite outcomes). This composite outcome is 


\section{4 women with breech fetus at term}

117 women excluded:

- 22 delivered during transition period

- 11 fetus had severe malformations (2 intrauterine fetal deaths)

- 22 had C-section for indications other

than a breech presentation

-62 were note enrolled in the

prospective period (not referred or refused)

162 women with breech

presentation at term before the

introduction of the breech clinic
115 women with breech

presentation at term after the

introduction of the breech clinic

retrospectively

included
28 were

prospectively

included

Fig. 2 Flow chart of patients

Table 1 Comparison of the three neonatal composite outcomes

\begin{tabular}{lll}
\hline Term Breech Trial outcome & PREMODA outcome & Erasme breech clinic outcome \\
\hline Fetal or neonatal mortality & Fetal or neonatal mortality & Fetal or neonatal mortality \\
Birth trauma including: & Birth trauma including: & Birth trauma including: \\
- Subdural hematoma & - Subdural hematoma & - Subdural hematoma \\
- Intracerebral or intraventricular haemorrhage & - Intracerebral or intraventricular haemorrhage & - Intracerebral or intraventricular haemorrhage \\
- Spinal cord injury & - Spinal cord injury & - Spinal cord injury \\
- Basal skull fracture & - Basal skull fracture & - Basal skull fracture \\
- Peripheral-nerve injury present at discharge & - Peripheral-nerve injury present at discharge & - Peripheral-nerve injury present at discharge \\
- Clinically significant genital injury & - Clinically significant genital injury & - Clinically significant genital injury \\
Seizures occurring at less than $24 \mathrm{~h}$ of age or & Seizures occurring at less than 24 $\mathrm{h}$ & Seizures occurring at less than $24 \mathrm{~h}$ of age or \\
requiring two or more drugs to control them & of age & requiring two or more drugs to control them \\
Five-minute Apgar score of less than four & Five-minute Apgar score of less than & Five-minute Apgar score of less than four \\
& four & \\
Cord-blood base deficit of at least 15 & $/$ & Cord-blood base deficit of at least 15 \\
Hypotonia for at least $2 \mathrm{~h}$ & $/$ & $/$ \\
Stupor & $/$ & $/$ \\
Decreased response to pain, or coma & $/$ & $/$ \\
Intubation and ventilation for at least $24 \mathrm{~h}$ & Intubation and ventilation for at least $24 \mathrm{~h}$ & Intubation and ventilation for at least $24 \mathrm{~h}$ \\
Tube feeding for 4 days or more & Parenteral or tube feeding for at least 4 days & Parenteral or exclusive tube feeding for at least \\
Admission to the neonatal intensive care unit & Admission to the neonatal intensive care unit for & Admission to the neonatal intensive care unit \\
for longer than 4 days & longer than 4 days & for longer than 4 days \\
\hline
\end{tabular}


defined as one or more of the following: neonatal death, five-minute Apgar score under four, arterial cord blood base deficit above $15 \mathrm{mEq} / \mathrm{L}$, neonatal trauma (brachial plexus injury or parietal skull fracture), NICU admission, NICU admission for over 4 days, parenteral or exclusive tubal feeding more than 4 days, seizures more than $24 \mathrm{~h}$, intraventricular haemorrhage and intubation or noninvasive ventilation for more than $24 \mathrm{~h}$.

We decided not to analyse the external cephalic version in this study.

\section{Analysis}

Baseline maternal characteristics, rates of planned vaginal deliveries, rates of actual vaginal deliveries and neonatal outcomes before and after the implementation of the breech clinic were compared.

A chi-square test was used to compare categorical variables (ethnicity, smoking, parity, uterine scar, ECV attempts, the mode of delivery, neonatal death, 5 min Apgar score, arterial cord blood $\mathrm{pH}$ under seven, arterial cord blood base deficit more than 12 or $15 \mathrm{mEq} / \mathrm{L}$, NICU admission, parenteral or tubal feeding and duration, intraventricular haemorrhage, non-invasive ventilation or intubation and the neonatal composite outcome). For continuous variables (maternal age, BMI, birth weight) a t-test was used after confirming that data was normally distributed. OR and the $95 \%$ CI were computed. A two-sided $p$-value of less than 0.05 was defined as statistically significant. Statistical analyses were performed using Stata version 12.

\section{Results}

In total, there were 394 women with a fetus in breech presentation at the delivery from the 1st of January 2013 to the 1st of October 2019. A total of 117 women were excluded from further analysis: 22 delivered during the transition period, 11 had a baby with severe fetal malformations (two were intrauterine deaths), 22 had a Csection for indications other than a breech presentation and 62 were not enrolled for the prospective part of the study from the 1st of March 2018 (women were either not referred for enrolment or refused to participate). There were 162 women with a fetus in breech presentation at the delivery during the period prior the introduction of the breech clinic and 115 women since the dedicated breech clinic was in operation (Fig. 2).

There was no statistically significant difference between both groups concerning the baseline maternal characteristics except for the ECV rate (Table 2). The

Table 2 Baseline characteristics

\begin{tabular}{|c|c|c|c|}
\hline & $\begin{array}{l}\text { Before }(\boldsymbol{n}=162) \\
\text { n (\%) }\end{array}$ & $\begin{array}{l}\text { After }(\boldsymbol{n}=115) \\
\mathrm{n}(\%)\end{array}$ & $\boldsymbol{p}$-value \\
\hline \multicolumn{4}{|l|}{ Maternal age in years } \\
\hline$<21$ years & $3(1.9 \%)$ & 0 & 0.34 \\
\hline $21-34$ years & 115 (70.9\%) & $82(71.3 \%)$ & \\
\hline$\geq 35$ years & $44(27.2 \%)$ & $33(28.7 \%)$ & \\
\hline Body mass index & (/162 observations) & (/113 observations) & \\
\hline$<18.5$ & $5(3.1 \%)$ & $5(4.4 \%)$ & 0.44 \\
\hline $18.5-24$ & $95(58.6 \%)$ & $69(61.1 \%)$ & \\
\hline $25-30$ & $34(21 \%)$ & $27(23.9 \%)$ & \\
\hline$>30$ & $28(17.3 \%)$ & $12(10.6 \%)$ & \\
\hline Ethnic origin & & & 0.77 \\
\hline European & $64(39.5 \%)$ & $54(47 \%)$ & \\
\hline Mediterranean Basin & $54(33.3 \%)$ & $32(27.8 \%)$ & \\
\hline Sub-saharan Africa & $16(9.9 \%)$ & $3(2.6 \%)$ & \\
\hline Other & $28(17.3 \%)$ & $26(22.6 \%)$ & \\
\hline Assisted reproductive technology & $9(5.6 \%)$ & $8(6.9 \%)$ & 0.6 \\
\hline \multirow[t]{2}{*}{ Smoking } & $21(14.7 \%)$ & $12(11.9 \%)$ & 0.53 \\
\hline & (/143 observations) & (/101 observations) & \\
\hline Primiparity & 99 (61.1\%) & $62(53.9 \%)$ & 0.23 \\
\hline Uterine scar & 19 (11.7\%) & $8(6.9 \%)$ & 0.19 \\
\hline External cephalic version & $103(63.6 \%)$ & 92 (80\%) & $\begin{array}{l}0.003 \\
\text { OR: } 2.3 \text { (95\% Cl: } 1.3-4.0)\end{array}$ \\
\hline Gestational diabetes & $23(14.2 \%)$ & $18(15.7 \%)$ & 0.74 \\
\hline Birth weight mean $( \pm S D)$ & $3317.6( \pm 432.1)$ & $3253.8( \pm 369.6)$ & 0.20 \\
\hline
\end{tabular}

$P$-value $<0.05$ considered statistically significant. OR Odds Ratio; Cl Confidence Interval; SD Standard Deviation; BMI Body Mass Index 
rate of ECV attempts increased from $63.6 \%$ before to 80.0\% (OR 2.3; 95\% CI 1.3-4.0) after the introduction of the breech clinic. There was no statistically significant difference between both groups concerning the labour characteristics of planned vaginal breech births (Table 3). A statistically significant increase in planned vaginal deliveries from 7.4 to $52.2 \%$ (OR 13.5; 95\% CI 6.7-27.0) was observed after the introduction of the breech clinic. The total proportion of vaginal breech delivery (planned and unexpected) has statistically significantly increased from 4.3\% (7/162) before implementation of the breech clinic to $43.5 \%$ (50/115) after the implementation (OR 17.0; 95\% CI 7.3-39.6). Finally, a reduction in unexpected breech births from 9.3 to $3.5 \%$ was also observed (OR 0.3; 95\% CI 0.1-0.9) (Table 4). Regarding the neonatal outcomes, there was no statistically significant difference before and after the start of the breech delivery pathway. However, we observed a slight trend towards a higher rate of arterial cord blood $\mathrm{pHs}<7$, of arterial cord blood base deficit $>12 \mathrm{mEq} / \mathrm{L}$, and noninvasive ventilation $>24 \mathrm{~h}$ (Table 5). There was no case of invasive ventilatory support for more than 24 $\mathrm{h}$ or of non-invasive ventilation for more than 4 days. We observed less five-minute Apgar scores under four and under seven, less parenteral or tubal feeding longer than 4 days and less NICU admissions following the implementation of the breech clinic. Finally, there was no statistically significant difference between the two groups for the composite neonatal outcome. There were nine newborns with arterial cord blood $\mathrm{pH}<7$ and/or five-minute Apgar score under four whose details are listed in Table 6. Only one of these newborns spent more than 4 days in the NICU but required neither ventilation more than 4 days nor parenteral feeding. The two other babies who spent more than 4 days in the NICU had five-minute Apgar scores $>7$ or normal arterial cord blood pHs at birth. One of the nine newborns, who was born by planned $\mathrm{C}$-section, required parenteral feeding for more than 4 days. Lastly, the breech presentation was unexpected for three of the babies with an adverse neonatal outcome, all were born by emergency $\mathrm{C}$-section.

Table 3 Labour characteristics of planned vaginal breech birth

\begin{tabular}{llll}
\hline & $\begin{array}{l}\text { Before }(n=12) \\
\mathrm{n}(\%)\end{array}$ & $\begin{array}{l}\text { After }(n=60) \\
\mathrm{n}(\%)\end{array}$ & $p$-value \\
\hline Induction of labour & $2(16.7 \%)$ & $6(10 \%)$ & 0.5 \\
Epidural & $10(62.5 \%)$ & $26(40.6 \%)$ & 0.74 \\
Augmentation of labour & $6(50 \%)$ & $23(38.3 \%)$ & 0.45 \\
Expulsion efforts > 60 min & $1(12.5 \%)$ & $11(20.4 \%)$ & 0.6 \\
Episiotomy & $4(50 \%)$ & $9(30 \%)$ & 0.29 \\
\hline
\end{tabular}

$p$-value $<0.05$ considered statistically significant
Table 4 Decision and mode of delivery before and after the introduction of the breech clinic

\begin{tabular}{lllll}
\hline & $\begin{array}{l}\text { Before } \\
(n=162)\end{array}$ & $\begin{array}{l}\text { After } \\
(n=115)\end{array}$ & OR & $95 \% \mathrm{Cl}$ \\
\hline Unexpected breech delivery & $15(9.3 \%)$ & $4(3.5 \%)$ & 0.3 & $0.1-0.9$ \\
Planned vaginal delivery & $12(7.4 \%)$ & $60(52.2 \%)$ & 13.5 & $6.7-27.0$ \\
Effective vaginal delivery & $7(4.3 \%)$ & $50(43.5 \%)$ & 17.0 & $7.3-39.6$ \\
\hline
\end{tabular}

OR Odds Ratio; Cl Confidence Interval

\section{Discussion}

This study has clearly demonstrated significant clinical differences for singleton breech presentations at term, before and after the introduction of a specialised breech clinic and care pathway. Prior to the development of the breech clinic the $\mathrm{C}$-section rate for breech presentation at term was $95.7 \%$ probably as a consequence of the TBT [2], whose impact has been observed in several countries [14, 27-29]. The C-section rate for breech presentation at term after the introduction of the breech clinic was $56.5 \%$. Using a specific management protocol for women with breech presentation, a statistically significant increase in proportion of planned and actual vaginal breech births and a statistically significant decrease in those unexpected were observed. Perhaps, more importantly, the increased rate of planned and successful vaginal breech births was not associated with a significant increase in adverse neonatal outcomes. However, we noticed there was a non-significant trend towards an increase in arterial cord blood $\mathrm{pHs}<7$ and arterial cord blood base deficit $>12 \mathrm{mEq} / \mathrm{L}$. This trend may be explained by the observed significant increase in vaginal deliveries following the implementation of the breech clinic in a service where breech presentation was previously managed with C-section in $95 \%$ of cases. The overall rate of adverse neonatal outcomes was relatively high in both groups. This cannot be explained by differences in the maternal or labour characteristics between the two groups. However, breech presentation itself and not solely the mode of delivery appears to increase perinatal mortality and severe morbidity [30]. In the PREMODA study, breech presentation was associated with increased perinatal mortality and severe morbidity with odds ratios of 1.60 (95\% CI 1.14-2.17) in the planned vaginal delivery group and of 1.45 (95\% CI 1.16-1.81) in the planned $\mathrm{C}$-section delivery group. Publications on the impact of equivalent breech services are scarce. Hejl et al. [31] also noticed an increased planned vaginal rate following the introduction of a specific protocol for breech presentations in their French level III maternity. Their rate of planned vaginal delivery increased from $32.7 \%$ in 2008 to $63.8 \%$ in $2014(p<0.05)$ with a reduction in their rate of emergency $\mathrm{C}$-sections from 26.2 to $20 \%(\mathrm{p}<0.05)$. In another French level III University Hospital study, Michel et al. [32] reported similar results 
Table 5 Neonatal morbidity and mortality

\begin{tabular}{|c|c|c|c|c|}
\hline & Before $(\boldsymbol{n}=162)$ & After $(\boldsymbol{n}=115)$ & OR & $95 \% \mathrm{Cl}$ \\
\hline & n (\%) & n (\%) & & \\
\hline Five-minute Apgar score $<4^{*}$ & $2(1.2 \%)$ & $1(0.9 \%)$ & 0.7 & $0.1-7.8$ \\
\hline Five-minute Apgar score $<7$ & $5(3.1 \%)$ & $4(3.5 \%)$ & 1.1 & $0.3-4.3$ \\
\hline Arterial cord blood $\mathrm{pH}<7$ & $1(0.6 \%)$ & $5(4.4 \%)$ & 7.3 & $0.8-63.5$ \\
\hline Arterial cord blood base deficit $\geq 12 \mathrm{mEq} / \mathrm{L}$ & $2(1.2 \%)$ & $6(5.2 \%)$ & 4.4 & $0.9-22.2$ \\
\hline Arterial cord blood base deficit $\geq 15 \mathrm{mEq} / \mathrm{L}^{*}$ & 0 & 0 & / & / \\
\hline NICU admission & $14(8.6 \%)$ & $8(6.9 \%)$ & 0.8 & $0.3-1.9$ \\
\hline$>4$ days* & $2(1.2 \%)$ & $2(1.7 \%)$ & 1.41 & $0.2-10.2$ \\
\hline Parenteral or exclusive tubal feeding & $4(2.5 \%)$ & $5(4.4 \%)$ & 1.8 & $0.5-6.8$ \\
\hline$>4$ days* & $1(0.6 \%)$ & 0 & l & / \\
\hline Birth trauma (severe hematoma)* & 0 & $1(0.9 \%)$ & l & / \\
\hline Intubation or ventilation & $9(5.6 \%)$ & $6(5.2 \%)$ & 0.9 & $0.3-2.7$ \\
\hline$>24 h^{*}$ & $1(0.6 \%)$ & $2(1.7 \%)$ & 2.9 & $0.3-31.8$ \\
\hline$>4$ days & 0 & 0 & / & / \\
\hline Seizures* & 0 & 0 & / & / \\
\hline Neonatal death* & 0 & 0 & / & / \\
\hline IVH grade I* & $1(0.6 \%)$ & 0 & / & / \\
\hline Composite neonatal outcome & $5(3.1 \%)$ & $4(3.5 \%)$ & 1.1 & $0.3-4.3$ \\
\hline
\end{tabular}

OR Odds ratio; CI Confidence interval; NICU Neonatal intensive care unit; $I V H$ intraventricular haemorrhage. *Criteria included in the combined outcome "Composite neonatal outcome"

following the introduction of a special service protocol for breech presentations. They observed an increase in planned vaginal delivery from 30.0 to $44.5 \%(p<0.01)$ and in successful vaginal deliveries for breech presentations from $24.0 \%$ in $2000-2004$ to $38.5 \%$ in $2004-2008$ $(p<0.001)$. Hejl et al. [31] also reported an increased rate of arterial cord blood $\mathrm{pH}<7.1$ from $1.8 \%(1 / 40)$ to $8.7 \%(8 / 92)(p=0.04)$. NICU admission was required for $12.4 \%$ of babies after the introduction of the protocol, which is higher than our rate (6.9\%). In contrast, Michel et al. [32] did not observe any statistically significant difference in neonatal outcomes before and after the application of their protocol. They reported an incidence of arterial cord blood $\mathrm{pH}<7$ of only $1.3 \%$ with their new protocol (compared to $4.4 \%$ in our study), $0.3 \%$ of 5 -min Apgar score (compared to $3.5 \%$ in our study) and $0.1 \%$ of NICU admission. Their chosen composite neonatal outcome, similar to the one that used by the TBT [2] and the PREMODA group [7], at $0.7 \%$ was comparable between the two modes of birth (compared to $3.5 \%$ in our study) [32]. The rate of NICU admission decreased after the introduction of the breech clinic, nonetheless, this rate remains relatively high. However, it is important to note that the local threshold to admit newborns for surveillance in the NICU is low and admission per se is not necessarily an accurate indicator of either short or long-term outcomes. For example, the neonatal admission rate for term babies in Flanders (the northern part of Belgium) during 2018 was $11.1 \%$ [33]. A study in the United States showed that the neonatal admission rate at $>34$ weeks is around $10 \%$ but varies greatly from 1.1 to $37 \%$ across NICUs and only $11 \%$ of those admissions were associated with high illness acuity criteria [34]. Low arterial cord blood $\mathrm{pHs}$ have been associated with more complications especially NICU admissions and seizures $[35,36]$. Nonetheless some authors [37, 38] concluded that neonatal morbidity with an arterial cord blood $\mathrm{pH}$ $<7$ can only be predicted when associated with low fiveminute Apgar score and/or an important arterial cord blood base deficit. However, in the composite outcome used in our study which is inspired by Hannah et al. [2] and the PREMODA Study [7], the arterial cord blood $\mathrm{pH}$ was not used. In our series of newborns with adverse short-term perinatal outcomes only three of them had $\mathrm{pH} \leq 7$ (one $\mathrm{pH}=7$, two $\mathrm{pH}<7$ ) combined with a fiveminute Apgar score under seven (none under four). Only one of these three babies, who was born after a planned vaginal delivery, had a long stay in neonatal intensive care (defined as more than 4 days and of 5 days in this case) and more than $24 \mathrm{~h}$ ' ventilation (but less than four days). None of them experienced seizures. Two of these had a prolonged second stage more than 60 min but only one stayed more than 4 days in the NICU with ventilation less than 4 days and no other complication. One of them, which was an unexpected breech delivery at term born by emergency C-section, 


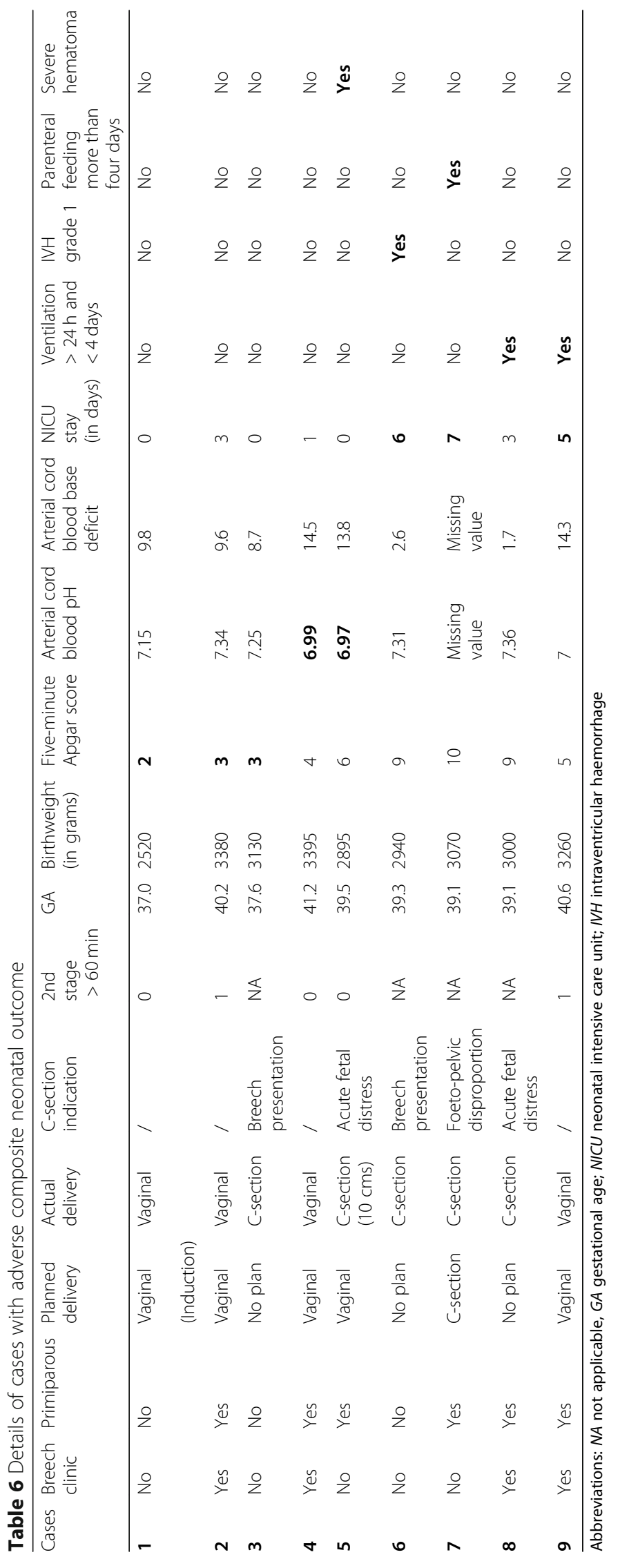


suffered a grade I intraventricular haemorrhage. We cannot report any relationship between the short-term adverse neonatal outcomes. The implementation of a breech presentation pathway has led to a statistically significant decrease in unexpected breech births. This decrease is important as one third of the newborns with an adverse perinatal outcome were unexpected breech presentations. The proportion of non-significant adverse short-term outcomes that we have observed, will probably improve with increasing experience. We remain vigilant, even though there is no evidence in the literature that adverse short-term outcomes impact on longer-term outcomes. Ulander et al. report no difference in long-term outcomes between breech and cephalic babies born vaginally [39]. Two studies, including the TBT, compared the long-term outcomes of breech presentations born vaginally or by C-section and found no differences $[10,40]$.

In Europe, the Nordic countries also promote vaginal breech delivery however we found no reports of breech clinics in these regions. In 2010, Daviss et al. reporting on a national survey of Canadian maternities described a lack of enthusiasm for the creation of breech clinics. In this study, only one centre (out of 20 responders) considered that a breech clinic was feasible and desirable and two other hospitals considered forming a breech team [41]. Our breech clinic is the first one of its kind in Belgium, the results thus far are encouraging, and this gives us confidence and motivation to continue with this dedicated care pathway. Our intended purpose was to support women in their choice and in this regard, we have been successful. Kok et al. reported that $35 \%$ of women will choose a vaginal delivery for their breech babies and in terms of factors influencing their decisions, it was the two-years neonatal outcome that was the most important piece of information affecting mode of birth for the expectant mothers while the fathers were more strongly influenced by the maternal outcomes [42]. The concentration of vaginal breech deliveries in dedicated centres is effective not only to avoid unnecessary Csections (because of practitioners lacking experience in breech delivery) but also to help improve the neonatal outcomes over time due to a growing expertise within the team.

The limitations of our study are the retrospective nature of the first part of the study and its lack of power, due to the sample size, to exclude differences in neonatal outcomes.

In this study, our objectives are not to demonstrate which factors are most important in avoiding a planned $\mathrm{C}$-section or an emergency $\mathrm{C}$-section for breech presentation. It is however plausible that our obstetricians and midwives, those directly working in the breech clinic and those not directly working in it, are now more confident in considering an attempt at vaginal birth, due to the existence of the clinic, the presence of an updated local protocol and the $24 \mathrm{~h}$ a day and 7 days a week on-call breech clinic dedicated obstetricians. As Walker et al. [19] suggest in their study, the expertise is developed by, among others factors, 'confidence and competence among colleagues' and the clinicians who have an interest in breech births should be supported within specialist teams. We also believe that the special preparatory sessions with doctors and midwives to discuss and plan their breech birth help to enhance women's confidence in the breech delivery process.

\section{Conclusion}

The implementation of a breech clinic in our hospital has led to a statistically significant increase in planned and observed vaginal deliveries for breech presentation at term without negatively impacting the rate of adverse neonatal outcomes.

\section{Supplementary information}

Supplementary information accompanies this paper at https://doi.org/10. 1186/s12884-020-03122-4.

Additional file 1. Leaflet of the breech clinic.

\begin{abstract}
Abbreviations
TBT: Term Breech Trial; FIGO: International Federation of Gynecology and Obstetrics; CNGOF: Collège National des Gynécologues et Obstétriciens Français; RCOG: Royal College of Obstetricians and Gynaecologists; SOGC: Society of Obstetricians and Gynaecologists of Canada; OR: Odds Ratio; 95\% Cl: 95\% confidence interval; ECV: External cephalic version; ULB : Université Libre de Bruxelles; GA: Gestational age; CT: Computerized tomography; NICU: Neonatal intensive care unit; BMI: Body mass index
\end{abstract}

\section{Acknowledgments}

We thank the breech clinic team: the midwives especially Chantal Baeyens, Mina Iman Alizadeh, Martine Pierreux and Marie Trullemans and the obstetrics team especially Christine Kirkpatrick, Anne Verougstraete and Siham Zaytouni and all our patients for their participation to our study. Finally, we are indebted to Andrew Carlin for his help preparing the manuscript.

\section{Authors' contributions}

SD was the principal investigator, participated in the implementation of the breech clinic, the elaboration of the study design, the recruitment of women, performed the collection and analysis of the data and the interpretation of the results and wrote the first draft of the manuscript. EC participated in the implementation of the breech clinic, the creation of the care pathway, the elaboration of the study design, the analysis of the data and the interpretation of the results. LDL participated in the recruitment of women and in the proofreading. SA participated in the recruitment of women and in the proofreading. VBK participated in the implementation of the breech clinic and in the proofreading. WHZ participated in the elaboration of the study design and in the proofreading. AV participated in the recruitment of women, in the writing and in the proofreading. SA participated in the interpretation of the results and in the proofreading. PMB participated in the study design and in the proofreading. YE contributed to the implementation of the breech clinic. AP participated in the proofreading of the manuscript. CD participated in the implementation of the breech clinic, the creation of the care pathway, the recruitment of women, the interpretation of the results and in the proofreading of the manuscript. All the authors read and approved the final manuscript. 


\section{Funding}

None.

\section{Availability of data and materials}

The datasets used and/or analysed during the current study are available from the corresponding author on reasonable request.

\section{Ethics approval and consent to participate}

This study was approved by the local ethics committee on the 15th of December 2017 ('Hôpital Erasme' ethics committee number: P2017/510 and CCB number: B406201733940). With agreement of the ethics committee, for the retrospective part of the study, there was no need for informed consent and no notification of their refusal to be involved in a study. From the 1st of March 2018, the patients were prospectively included and gave their written informed consent to participate to the study.

\section{Consent for publication}

Not applicable.

\section{Competing interests}

The authors declare no competing interests.

\section{Author details}

'Department of Obstetrics and Gynecology, Cliniques Universitaires de Bruxelles, Hôpital Erasme, Université Libre de Bruxelles (ULB), 808 route de Lennik, B-1070 Bruxelles, Belgium. ${ }^{2}$ Research Laboratory for Human Reproduction, Faculty of Medicine, Université Libre de Bruxelles (ULB), 808 route de Lennik, CP 597, B-1070 Bruxelles, Belgium. ${ }^{3}$ Perinatal Epidemiology and Reproductive Health Unit, Epidemiology, Biostatistics and Clinical Research Centre, Ecole de Santé Publique, Université Libre de Bruxelles (ULB), Bruxelles, Belgium. ${ }^{4}$ Department of Epidemiology, School of Public Health and Tropical Medicine, Tulane University, New Orleans, Louisiana, USA.

Received: 14 March 2020 Accepted: 21 July 2020

Published online: 29 July 2020

\section{References}

1. Impey L, Murphy D, Griffiths M, Penna L. Management of Breech Presentation. BJOG Int J Obstet Gynaecol. 2017;124(7):e151-77.

2. Hannah ME, Hannah WJ, Hewson SA, Hodnett ED, Saigal S, Willan AR. Planned caesarean section versus planned vaginal birth for breech presentation at term: a randomised multicentre trial. Term Breech Trial Collaborative Group. Lancet Lond Engl. 2000;356(9239):1375-83.

3. Kunzel W. Recommendations of the FIGO Committee on Perinatal Health on guidelines for the management of breech delivery. Eur J Obstet Gynecol Reprod Biol. 1995;58(1):89-92

4. Sentilhes L, Schmitz T, Azria E, Gallot D, Ducarme G, Korb D, et al. Breech presentation: CNGOF guidelines for clinical practice - short text. Gynecol Obstet Fertil Senol. 2020:48(1):63-9.

5. Kotaska A, Menticoglou S. No. 384-Management of Breech Presentation at Term. J Obstet Gynaecol Can. 2019:41(8):1193-205.

6. Azria É. Breech presentation: CNGOF guidelines for clinical practice - case selection for trial of labour. Gynecol Obstet Fertil Senol. 2020;48(1):120-31.

7. Goffinet F, Carayol M, Foidart J-M, Alexander S, Uzan S, Subtil D, et al. Is planned vaginal delivery for breech presentation at term still an option? Results of an observational prospective survey in France and Belgium. Am J Obstet Gynecol. 2006;194(4):1002-11.

8. Glezerman M. Five years to the term breech trial: the rise and fall of a randomized controlled trial. Am J Obstet Gynecol. 2006;194(1):20-5.

9. Carbonne B. Hannah's term breech trial: For whom the bell tolls? Gynecol Obstet Fertil. 2006:34(9):677-8.

10. Whyte H, Hannah ME, Saigal S, Hannah WJ, Hewson S, Amankwah K, et al Outcomes of children at 2 years after planned cesarean birth versus planned vaginal birth for breech presentation at term: the international randomized term breech trial. Am J Obstet Gynecol. 2004;191(3):864-71.

11. Molkenboer JFM, Bouckaert PXJM, Roumen FJME. Recent trends in breech delivery in the Netherlands. BJOG Int J Obstet Gynaecol. 2003;1 10(10):948-51.

12. Alexandersson $\mathrm{O}$, Bixo M, Högberg U. Evidence-based changes in term breech delivery practice in Sweden. Acta Obstet Gynecol Scand. 2005; 84(6):584-7.
13. Carayol M, Blondel B, Zeitlin J, Breart G, Goffinet F. Changes in the rates of caesarean delivery before labour for breech presentation at term in France: 1972-2003. Eur J Obstet Gynecol Reprod Biol. 2007; 132(1):20-6.

14. Lansac J, Crenn-Hebert C, Rivière O, Vendittelli F. How singleton breech babies at term are born in France: a survey of data from the AUDIPOG network. Eur J Obstet Gynecol Reprod Biol. 2015;188:79-82.

15. Su M, McLeod L, Ross S, Willan A, Hannah WJ, Hutton E, et al. Factors associated with adverse perinatal outcome in the term breech trial. Am J Obstet Gynecol. 2003;189(3):740-5.

16. 19 Siège et VME - protocole GGLOFB 2017.pdf Available: https://www. ggolfb.be/sites/default/files/article/file/19\%20\%20Sie\%CC\%80ge\%20et\%2 OVME\%20-\%20protocole\%20GGLOFB\%202017.pdf.

17. Euro-Peristat Project. European perinatal health report. Core indicators of the health and care of pregnant women and babies in Europe in 2015. 2018. Available www.europeristat.com.

18. Walker S, Scamell M, Parker P. Standards for maternity care professionals attending planned upright breech births: a Delphi study. Midwifery. 2016;34:7-14.

19. Walker S, Parker P, Scamell M. Expertise in physiological breech birth: a mixed-methods study. Birth. 2018;45(2):202-9.

20. Thissen D, Swinkels P, Dullemond RC, van der Steeg JW. Introduction of a dedicated team increases the success rate of external cephalic version: a prospective cohort study. Eur J Obstet Gynecol Reprod Biol. 2019;236:193-7

21. Fraser W, Maunsell E, Hodnett E, Moutquin JM. Randomized controlled trial of a prenatal vaginal birth after cesarean section education and support program. Childbirth Alternatives Post-Cesarean Study Group Am J Obstet Gynecol. 1997:176(2):419-25.

22. Rovner P, Stickrath E, Alston M, Lund K. An early pregnancy unit in the United States: an effective method for evaluating first-trimester pregnancy complications. J Ultrasound Med. 2018;37(6):1533-8.

23. Welffens $K$, Derisbourg $S$, Costa E, Englert $Y$, Pintiaux A, Warnimont $M$, et al. The "Cocoon, » first alongside midwifery-led unit within a Belgian hospital: Comparison of the maternal and neonatal outcomes with the standard obstetric unit over 2 years. Birth. 2020;47(1):115-22.

24. Walker S, Breslin E, Scamell M, Parker P. Effectiveness of vaginal breech birth training strategies: an integrative review of the literature. Birth. 2017:44(2):101-9.

25. Walker S, Perilakalathil P, Moore J, Gibbs CL, Reavell K, Crozier K. Standards for midwife practitioners of external cephalic version: a Delphi study. Midwifery. 2015;31(5):e79-86.

26. Louwen F, Daviss B-A, Johnson KC, Reitter A. Does breech delivery in an upright position instead of on the back improve outcomes and avoid cesareans? Int J Gynaecol Obstet Off Organ Int Fed Gynaecol Obstet. 2017; 136(2):151-61.

27. Hartnack Tharin JE, Rasmussen S, Krebs L. Consequences of the term breech trial in Denmark. Acta Obstet Gynecol Scand. 2011;90(7):767-71.

28. Rietberg CCT, Elferink-Stinkens PM, Visser GHA. The effect of the term breech trial on medical intervention behaviour and neonatal outcome in the Netherlands: an analysis of 35,453 term breech infants. BJOG Int J Obstet Gynaecol. 2005;112(2):205-9.

29. Sullivan EA, Moran K, Chapman M. Term breech singletons and caesarean section: a population study, Australia 1991-2005. Aust N Z J Obstet Gynaecol. 2009:49(5):456-60.

30. Carbillon L, Benbara A, Tigaizin A, Murtada R, Fermaut M, Belmaghni F, et al. Revisiting the management of term breech presentation: a proposal for overcoming some of the controversies. BMC Pregnancy Childbirth may. 2020;20(1):263.

31. Hejl L, Perdriolle-Galet E, Gauchotte E, Callec R, Morel O. Vaginal delivery in case of breech presentation: Impact of a service's incentive. Gynecol Obstet Fertil Senol. 2017:45(11):596-603.

32. Michel S, Drain A, Closset E, Deruelle P, Ego A, Subtil D, et al. Evaluation of a decision protocol for type of delivery of infants in breech presentation at term. Eur J Obstet Gynecol Reprod Biol. 2011;158(2):194-8.

33. Devlieger R, Goemaes R, Laubach M. Perinatale Activiteiten In Vlaanderen, vol. 61; 2018.

34. Schulman J, Braun D, Lee HC, Profit J, Duenas G, Bennett MV , et al. Association between neonatal intensive care unit admission rates and illness acuity. JAMA Pediatr. 2018:172(1):17-23.

35. Malin GL, Morris RK, Khan KS. Strength of association between umbilical cord $\mathrm{pH}$ and perinatal and long term outcomes: systematic review and meta-analysis. BMJ. 2010;340:c1471. 
36. Knutzen L, Anderson-Knight H, Svirko E, Impey L. Umbilical cord arterial base deficit and arterial $\mathrm{pH}$ as predictors of adverse outcomes among term neonates. Int I Gynecol Obstet. 2018;142(1):66-70.

37. Sehdev HM, Stamilio DM, Macones GA, Graham E, Morgan MA. Predictive factors for neonatal morbidity in neonates with an umbilical arterial cord pH less than 7.00. Am J Obstet Gynecol. 1997;177(5):1030-4.

38. Anyaegbunam A, Fleischer A, Whitty J, Brustman L, Randolph G, Langer O. Association between umbilical artery cord pH, five-minute Apgar scores and neonatal outcome. Gynecol Obstet Investig. 1991;32(4):220-3.

39. Ulander V-M, Gissler M, Nuutila M, Ylikorkala O. Are health expectations of term breech infants unrealistically high? Acta Obstet Gynecol Scand. 2004; 83(2):180-6

40. Macharey G, Väisänen-Tommiska M, Gissler M, Ulander V-M, Rahkonen L, Nuutila $M$, et al. Neurodevelopmental outcome at the age of 4 years according to the planned mode of delivery in term breech presentation: a nationwide, population-based record linkage study. J Perinat Med. 2018; 46(3):323-31.

41. Daviss B-A, Johnson KC, Lalonde AB. Evolving evidence since the term breech trial: Canadian response, European dissent, and potential solutions. J Obstet Gynaecol Can. 2010;32(3):217-24.

42. Kok M, Gravendeel L, Opmeer BC, van der Post JAM, Mol BWJ. Expectant parents' preferences for mode of delivery and trade-offs of outcomes for breech presentation. Patient Educ Couns. 2008;72(2):305-10.

\section{Publisher's Note}

Springer Nature remains neutral with regard to jurisdictional claims in published maps and institutional affiliations.

Ready to submit your research? Choose BMC and benefit from:

- fast, convenient online submission

- thorough peer review by experienced researchers in your field

- rapid publication on acceptance

- support for research data, including large and complex data types

- gold Open Access which fosters wider collaboration and increased citations

- maximum visibility for your research: over $100 \mathrm{M}$ website views per year

At BMC, research is always in progress.

Learn more biomedcentral.com/submissions 